\title{
ОБРІЇ РОЗВИТКУ АДАПТИВНОГО НАВЧАННЯ
}

\section{О. П. Мінцер}

\author{
Національна медична академія післядипломної освіти імені П. Л. Шупика
}

Досліджено можливість суттєвого підвищення якості навчання в післядипломній медичній освіті шляхом направленого змінення послідовності модулів знань, їхніх розмірів, форм подачі навчального матеріалу тощо, комплементарного до рівня знань суб'єкту навчання. Запропонована модульна структура платформи навчання в післядипломній медичній освіті.

Ключові слова: адаптивні технології навчання, інтелектуальні технології навчання, автоматизовані навчальні системи, індивідуально спланована послідовність модулів знань для навчання, системи управління навчанням.

\section{ПЕРСПЕКТИВЫ РАЗВИТИЯ АДАПТИВНОГО ОБУЧЕНИЯ}

\section{О. П. Минцер}

Национальная медицинская академия последипломного образования имени П. Л. Шупика

Исследована возможность существенного повышения качества обучения в последипломном медицинском образовании путем направленного изменения последовательности модулей знаний, их размеров, форм подачи учебного материала и т. д., комплементарного уровню знаний обучаемого. Предложена модульная структура платформы обучения в последипломном медицинском образовании.

Ключевые слова: адаптивные технологии обучения, интеллектуальные технологии обучения, автоматизированные обучающие системы, индивидуально спланированная последовательность модулей знаний для обучения, системы управления обучением.

\section{PROSPECTS OF THE ADAPTIVE LEARNING DEVELOPMENT}

\section{Shupyk National Medical Academy of Postgraduate Education}

O. P. Mintser

The possibility of significant increase in the quality of learning in postgraduate medical education by directed reorder of knowledge modules, its size and shape of educational material supply, etc. complementary to the knowledge of the student is investigated. The modular platform training in postgraduate medical education is proposed.

Key words: adaptive learning technology, intelligent learning technology, automated training systems, individually planned sequence of knowledge modules for teaching, learning management systems. 
Вступ. Більше ніж очевидно, що електронне навчання революційним шляхом змінить способи отримання знань та навиків. Уже сьогодні на ринку освіти функціонують тисячі постачальників систем управління навчанням (СУН) (англ. Learning Management System - LMS). Десятки СУН пропонується на вибір. Ринок СУН у 2018 році, як очікується, становитиме понад 7 млрд дол. США [15]. Прогнозується, що до 2019 року приблизно половина всіх навчальних закладів буде використовувати електронне навчання [18]. В результаті, інтерес до СУН безперервно збільшується.

Останнім часом активно розвивається новий напрям у сфері комп'ютеризованого навчання, що отримав назву адаптивних та інтелектуальних технологій передавання знань [11-14]. Завдання цього напряму досліджень - включити до навчальних систем можливості диференціації технологічного процесу передавання знань, тобто забезпечити врахування індивідуальних здібностей суб'єкту навчання, його попередніх знань та вмінь. До того ж на основі персональних можливостей суб'єкту навчання процес навчання проходить більш обгрунтованим для нього 3 погляду на якість та швидкість засвоєння знань.

При всій очевидності цього, здавалося б, простого висновку, в дійсності, все інакше.

Перш за все, в подібних системах визначення рівня знань суб'єкту навчання здійснюється шляхом інтерактивного діалогу з ним, що реалізувати достатньо складно з низки причин. Існує постійна необхідність проводити контроль і підтримку навчання в режимі реального часу, вдосконалювати стратегію навчання та тестування на основі індивідуального рівня знань, навиків і здібностей суб'єкту навчання. Необхідно використання сучасних систем навігації, оброблення та каталогізації даних для забезпечення ефективнішого використання величезних інформаційних ресурсів Інтернету, електронних бібліотек, баз даних і знань. При цьому система повинна володіти інтуїтивно зрозумілим інструментарієм, що дозволяє викладачу створювати, додавати, змінювати навчальний матеріал, курси, методи тестування й оцінювання знань, аналізувати результати навчання тощо.

Останніми роками адаптивне навчання сильно змінилося завдяки появі сервісу «Knewton» [17]. Розпочався такий період, коли кожний освітній додаток за замовчуванням - адаптивний [3, 7]. У навчальних системах реалізуються принципи відповідно до яких забезпечується ілюстрація, що суб'єкти навчання знають, наскільки вони готові до нових знань і як їх здібності розвиваються з часом. Зрозуміло, необхідно мати начальну інформацію, що взагалі потрібно знати суб'єкту навчання, та сформувати відповідний стандарт. Без складної інфраструктури, що поставляла б найсвіжіші дані про створені під час навчання знання та вміння суб'єкту навчання, цього зробити неможливо. Такі системи можуть лише робити припущення 3 певним значенням ймовірності. Важливо підкреслити, що похибка буде збільшуватися в геометричній прогресії з кожним новим рівнем, на який переходить суб'єкт навчання. Тому вкрай необхідними слід вважати постійну корекцію траєкторії навчання.

Ще один крок, зроблений на шляху вдосконалення СУН, пов'язаний з розробленням і впровадженням інтелектуальних навчаючих систем (IHC). Інтелектуальний аналіз рішень - це процедура перевірки, при якій навчальна система здатна проаналізувати відповіді суб'єкту навчання на тестові завдання, вказати, що саме неправильно чи неповно висвітлено у відповіді та, як наслідок, які знання недостатньо засвоєні суб'єктом навчання. В зв'язку з цим IHC можуть надавати суб'єктам навчання детальну інформацію про помилки та, відповідно, адаптувати навчальний процес до індивідуальних особливостей суб'єкту навчання [6].

Ця адаптація може включати, наприклад, постійний підбір і організацію структури наступної порції навчального матеріалу - залежно від того, які компоненти знання та процедури досліджуваного предмета засвоєно суб'єктом навчання i наскільки добре.

Також можуть враховуватися його емоційний і когнітивний стани, мотивація до навчання, навчальні цілі (підготовка до підсумкового екзамену 3 предмету або вивчення повного курсу «з нуля», в індивідуальних формах і темпі).

Інтелектуалізація комп'ютерного навчання передбачає використання методів і моделей подання інформації на базі систем, заснованих на знаннях.

Мета дослідження: запропонувати концептуальну модель адаптивних IHC у післядипломній медичній освіті.

Результати та їх обговорення. Теоретичні передумови та визначення. Введемо декілька визначень. Адаптивне навчання - технологічна педагогічна система, що сприяє ефективному індивідуальному навчанню. Вона має оцінювати початкову підготовку суб'єкту навчання та відсте- 
жувати результати проходження навчання, характеристики сприйняття нової інформації, забезпечити викладачеві можливість варіювати способи подачі матеріалу, а тому, кого навчають, способи його засвоєння, а також коригувати параметри, структуру й алгоритм навчання. Отже, ефективна технологія адаптивного та інтелектуального навчання має базуватися на позиції діяльного, активного, гнучкого підходу до побудови педагогічного процесу [4].

Адаптивне навчання має ряд відмінних рис. По-перше, необхідність попереднього контролю знань. По-друге, це необхідність певної надмірності, а також ретельної деталізації навчального курсу, структуризація навчального матеріалу, виділення самостійних частин курсу (кожна 3 них повинна бути логічно закінченою та представляти самостійний елемент). Нарешті має бути забезпечено встановлення залежностей між частинами навчального курсу [5].

Введемо також поняття інтерактивного навчання (IH), під яким будемо розуміти багаторазове повторення СУН дій, спроб тощо для досягнення фіксованої мети при постійних зовнішніх умовах [1]. Сталість зовнішніх умов дозволяє проводити кількісний опис IН у вигляді аналітичних залежностей (кривих навчання), що представляють визначення рівня навчання від часу або від числа ітерацій. За результативну характеристику IH приймається критерій рівня навчання - тимчасові, швидкісні, точності, інформаційні характеристики [15]. Навчання в загальному випадку - «процес і результат придбання індивідуального досвіду» [19].

Найважливішою метою СУН є побудова технології послідовності курсу навчання (технологія навчального планування). Іншими словами, потрібно забезпечити суб'єкта навчання індивідуально спланованою послідовністю блоків знань для засвоєння знань і послідовністю навчальних завдань для забезпечення його компетенцій.

Існує два істотно різних види побудови послідовностей: активні та пасивні. Активна побудова послідовності означає наявність мети навчання (підмножина понять сфери навчання або тим, чим треба оволодіти). Системи 3 активною послідовністю можуть побудувати кращий індивідуальний шлях для досягнення мети. Пасивна послідовність не вимагає активної мети навчання. Вона починає діяти, коли користувач не здатний вирішити задачу або відповісти на питання правильно. В цьому випадку, зазвичай, суб'єкту навчання пропонуються додаткові знання для знаходження помилки [8].
Класифікують адаптивні навчальні системи (АНC) за способом добірки чергової порції навчальної інформації (НI). Серед різних класифікаційних схем постійно можна знайти стохастичні, навігаційні та гібридні АНС. У стохастичної моделі стан суб'єкта навчання на деякому сеансі навчання описується вектором ймовірностей незнання кожного $з$ елементів НI, а чергова порція навчального матеріалу визначається ймовірністю незнання НI. Цей тип моделей представлений АНC на основі IH.

Швидкість навчання залежить від параметрів моделі: числа елементів, зв'язків і законів їх взаємодії. Знаючи цю залежність, можна запропонувати заходи, що призведуть до відповідної зміни параметрів моделі та необхідного збільшення швидкості навчання [2]. Алгоритм навчання полягає у виконанні 4 етапів: перевірці знань; на підставі перевірки знань суб'єкту навчання адаптуються параметри; коригується вектор незнання елементів навчальної інформації; обчислюється критерій якості навчання. Залежно від критерію якості навчання АНС вирішує: завершувати навчання або за певними правилами підбирати чергову порцію навчальної інформації [9]. У навігаційній АНС алгоритмічна модель пов'язана зі структурою знань, а в гібридній моделі вибір чергової порції НІ залежить від ймовірності незнання матеріалу та від зв'язків між блоками навчальної інформації.

Окремо слід зупинитися на навчальних адаптивних системах на базі Web-технологій [16]. 3 одного боку, системи у Web дійсно потребують адаптації, оскільки вони працюють із більшою кількістю відмінних один від одного користувачів, ніж системи, створені раніше та призначені для встановлення безпосередньо на машину користувача. 3 іншого боку, Web забезпечує доступність для значно більшої кількості реальних користувачів. У той час як адаптивна система встановлена на потужному сервері, що обслуговується та підтримується добре кваліфікованим персоналом, тисячі користувачів можуть працювати в навчальному середовищі, використовуючи дешеві комп'ютери [10].

Інтелектуальні адаптивні системи. Виділяють IHC та адаптивні гіпермедіа системи (АГС) [16]. Традиційно проблеми, що стосуються розробки СУН у напрямку IНC, пов'язані зі знаннями про структуризацію предметної області, а також зі стратегією навчання для підтримки гнучкого індивідуалізованого вивчення та навчання. Подібні IHC забезпечують інтерактивний діалог із суб'єктами навчання, проводять контроль і підтримку в режимі 
реального часу, дозволяють постійно вдосконалювати стратегію навчання та тестування на основі індивідуального рівня знань, навиків і здібностей.

АГС представляють автоматично персоналізований доступ до інформаційних гіпермедіа-ресурсів, частіше за все у формі \Уеь-сайтів [16]. Більшість АГС забезпечують підтримку адаптивної навігації та адаптивного змісту. Структура посилань або зображення показників посилань різниться для кожного користувача. Реальний зміст інформаційних сторінок також відрізняється для різних користувачів. Абстрактний рівень архітектурно складається 3 трьох частин:

- модель предметної області, що описує, яким чином структуровано зміст додатка (використовуючи концепти та відношення концептів);

- деталізована модель користувача, що представляє його інтереси, знання, цілі, історію навігації та інші релевантні аспекти;

- модель адаптації, що складається 3 правил адаптації. Правила визначають процес генерації адаптивного навчання й оновлення моделі користувача.

Підсумовуючи досвід створення адаптивних IHC, можна запропонувати таку структуру сучасної платформи навчання в післядипломній медичній освіті. Вона має складатися 3 двох кластерів, кожний із яких, своєю чергою, має 11 модулів.

Перший кластер складають:

1. Система збору даних. Ïї основне завдання отримання та акумуляція інформації про знання суб'єкта навчання. Основою її є адаптивна онтологічна структура, що відображає зв'язки між окремими поняттями та генерує потрібні системи, цілі й алгоритми взаємодії інформаційних моделей знань для лікарів і провізорів, які навчаються.

2. Обчислювальний блок. Він забезпечує оброблення та аналіз даних у реальному часі. Складовою системи адаптивного навчання $є$ контроль над засвоєнням отриманих знань суб'єктом навчання. Доцільність адаптивного контролю випливає 3 міркувань раціоналізації традиційного тестування. Використання завдань, що відповідають рівню підготовленості, істотно підвищує точність вимірювань і мінімізує час індивідуального тестування. Адаптивне навчання дозволяє забезпечити видачу навчальних завдань на оптимальному, приблизно $50 \%$ рівні складності. Зауважимо, що адаптивний контроль знань, зазвичай, розглядається в двох аспектах: методичному та технічному. До методичного відносяться: планування та організація проведення контролю; визначення типів питань і відбір завдань для перевірки знань; формування набору питань і завдань для опитування; визначення критеріїв оцінювання виконання кожного завдання та контрольної роботи в цілому тощо. До технічного аспекту відносяться: автоматичне формування набору контрольних завдань на основі обраного підходу; вибір і використання в системі контролю параметрів; вибір алгоритмів для оцінювання знань суб'єктів навчання тощо.

3. Система висновків. Модуль забезпечує нагромадження даних, а після їхнього оброблення робить відповідні висновки.

4. Психометричний блок. Оцінює знання та вміння суб'єкту навчання, підлаштовує параметри контенту. 3 кожним новим рівнем інформація про суб'єкт навчання стає в рази точніше.

5. Блок стратегії навчання. Оцінює чутливість суб'єктів навчання до змін у викладанні, темпі, оцінюванні тощо. Адаптивне навчання поєднує навчальну стратегію зі стратегією тестування, в якій заздалегідь відомі параметри та труднощі засвоєння. Відповідно, забезпечується диференціація кожного завдання. Така система створюється у вигляді комп'ютерного банку завдань, упорядкування яких може здійснюватися оперативно, відповідно до інтересів суб'єкту навчання та цільових функцій освіти. Найголовніша характеристика завдань адаптивного тесту - це рівень їх складності, отриманий дослідним шляхом. Кожен тест має проходити емпіричну апробацію на досить великій кількості типових суб'єктів навчання. Викладене дозволяє припустити, що адаптивна система має інтегруватися в систему особистісно-орієнтованого підходу до навчання.

6. Блок зворотного зв'язку. Об'єднує всі дані та передає в систему збору даних. Пропонується схема зворотного зв'язку по типу «відомої відповіді», що й мала б забезпечувати мотивацію, і невідомий (або, якщо навчання базується на повторенні, повторюваний) набір завдань, які забезпечують вивчення конкретного навчального матеріалу. В основі такого методу лежить припущення, що існує логіка прийняття рішень, яка й визначає поведінку навчальної системи. В той же час через незмінне ядро 
такої системи даний метод спрацьовує тільки для «середнього» суб'єкту навчання.

7. Система персоналізації. Використовує накопичені дані системи задля знаходження оптимальної стратегії для кожного суб'єкту навчання на кожному рівні. Сучасний стан розвитку СУН дозволяє стверджувати, що комп'ютер у змозі виявляти емоційний стан суб'єкту навчання шляхом вивчення виразу його обличчя, комп'ютерні програми здатні визначити рівень суб'єкту навчання, оцінити складність даного завдання. Відповідно створюється можливість адаптації навчальних матеріалів.

8. Блок рекомендацій. Повідомляє наступні кроки, коригує цілі, оцінює сильні та слабкі сторони суб'єкту навчання, ступінь залучення тощо.

9. Блок аналітичних прогнозів. Пророкує швидкість і вірогідність досягнення цілей (наприклад, ймовірність того, що суб'єкт навчання пройде тест, на 70 \%), очікувану оцінку, рівень знань тощо.

10. Єдина історія навчання. Рекомендовано створення особистої статистики суб'єкта навчання, що враховує успіхи в різних додатках і предметних областях.

11. Модуль вибору стратегії розгортання СУН. Пропонуються критерії вибору ефективної СУН: зіставлення технологій хмарного розгортання та технологій мережі 3 відкритим вихідним кодом; моделі ціноутворення процесів навчання; специфікація підтримки; характеристики людей, які будуть навчатися, тощо. Всі вони є важливими факторами для правильного вибору СУН.

На останок, виробництво адаптивних додатків справа дуже дорога, причому воно в рази дорожче і складніше, якщо будувати цілу платформу 3 гнучкими алгоритмами оцінювання, можливістю отримання даних щодо динаміки навчання, побудови на їх основі точних висновків. Саме тому важливо розробити відкриту інфраструктуру для збору, аналізу та використання даних про результат навчання в національному масштабі. На базі цієї платформи можливе створення адаптивних додатків, що можна приєднати до мережі, не витрачаючи сили та гроші на самостійну розробку всіх цих інструментів.

\section{Висновки.}

1. Адаптивне навчання - одна з найбільш ефективних і затребуваних технологій. Загальною тенденцією $є$ використання в найближчому майбутньому все більш складних систем. Відповідно, потребує суттєвого змінення СУН. Зокрема, слід підкреслити, що невід'ємною частиною СУН стають дані наукових досліджень, а також рекомендації щодо конкретного плану навчання для суб'єкту навчання. Це допомагає кожному суб'єкту навчання досягти цілей навчання персоналізованим способом.

2. Запропонована модульна структура платформи навчання в післядипломній медичній освіті.

\section{Література.}

1. Аванесов В. С. Теория и методика педагогических измерений: материалы публикаций. - М.: ЦТ и МКО УГТУ-УПИ, 2005. - 98 с.

2. Выродов А. П. Применение методов адаптивной гипермедиа при разработке автоматизированных обучающих систем / Выродов А. П., Костарев Д. Б., Ковалева С. В., Батрак А. Н. // Вісник Міжнар. слов'ян, ун-ту. Сер. Техн. науки. - 2008. - Т. 11, № 1. - С. 45-50.

3. Галеев И. Х. Развитие адаптивных технологий обучения / Галеев И. Х. // Вестник ВГУ - 2004. - № 4. - C. 76-83.

4. Гапонова В. М. Принципи та функції педагогічного тестового контролю / Гапонова В. М., Рабійчук Л. С. // Збірник наукових праць. - Хмельницький: Нац. акад. ПВУ 2002. - № 20, Ч. II. - С. 91-96.

5. Добровольський Г. А. Алгоритм створення тестових завдань /Добровольський Г. А., Савченко Т. В. - Запоріжжя: Запорізький національний університет, 2006. - C. 17-24.

6. Лукіна Т. О. Технології діагностики та оцінювання навчальних досягнень: навч.-метод, матеріали. - К.: Експрес-об'ява, 2007. - 62 с.

7. Мінцер О. П. Автоматизація адаптивних процесів в системі дистанційного навчання та контролю знань / Мінцер О. П. // Электроника и связь. - 2006. - № 3. - C. 87-91.

8. Самылкина Н. Н. Современные средства оценивания результатов обучения / Самылкина Н. Н. - М.: БИНОМ, Лаборатория знаний, 2007. - 172 с.

9. Титенко С. В. Ієрархічно-мережева модель управління освітнім контентом системи безперервного навчання / Титенко С. В., Гагарін О. О. // Системний аналіз та інформаційні технології: матеріали Х Міжнар. наук.-техн. конф., м. Київ, 20-24 травня 2008 р. - К: НТУУ «КПІ», 2008.

10.Топчиев А. В. Модели адаптивного обучения в компьютерных системах / Топчиев А. В., Чулюков В. А. // Современные наукоемкие технологии. - 2010. -№ 5. - C. 62-68. 
Н.Федорук П. И. Использование адаптивных и интеллектуальных технологий в системах дистанционного обучения / Федорук П. И. // УСиМ. - 2006. - № 5. - С. 68-73.

12. Федорук П. І. Адаптація інтелектуальних систем дистанційного навчання та контролю знань до індивідуальних особливостей студентів на основі аналізу якості засвоєних знань / Федорук П. І. // Штучний інтелект. - 2006. - № 3. - С. $480^{\wedge} 186$.

13. Федорук П. І. Технологія представлення моделі адаптивної системи дистанційного навчання та контролю знань / Федорук П. І. // Системи підтримки прийняття рішень. Теорія і практика: зб. доповідей наук.-практ. конф. 3 міжнар. участю. - К.: ІПММС НАНУ, 2006. - С. 186-190.

14. Федорук П. І. Технологія розробки навчального модуля в адаптивній системі дистанційного навчання та контролю знань / Федорук П. І. // Математичні машини і системи. - 2005. - № 3. - С. 155-165.

15. Calvi L. Towards generic adaptive systems: analysis of a case study / Calvi L., Cristea A. // In Proc. of the 2nd International Conf. on Adaptive Hypermedia and Adaptive Web-based Systems (Malaga, Spain, 2002). P. 79-89.

16.Dolog P. Challenges and benefits of the semantic web for user modelling. In Proc. of AH2003 - Workshop on adaptive hypermedia and adaptive web-based systems / Dolog P., Nejdl W. // Twelfth International World Wide Web Conference, Budapest, Hungary, May 20, 2003. Ninth International Conference on User Modeling, Johnstown, Pennsylvania, USA, June 22, 2003. Fourteenth Conference on Hypertext and Hypermedia Nottingham, UK, August 26, 2003. - P. 99-112.

17. One on one for everyone. The unique advantage of Knewton adaptive learning / Knewton. - Режим доступу: https://www.knewton.com/approach/.

18. Vasilakos T. Computational intelligence in web-based education: a tutorial / Vasilakos T., Devedzic V., Kinshuk K., Pedrycz W. // Journal of Interactive Learning Research (JILR). - 2004. - Vol. 15, No. 4. - P. 299-318.

19. $\mathrm{Wu} \mathrm{H}$. Sufficient conditions for well-behaved adaptive hypermedia systems / Wu H., De Bra P. // In Proc. of the First Asia-Pac Conf. on Web Intelligence: Research and Development (Maebashi City, Japan, 2001). P. 148-162.

\section{References.}

1. Avanesov, V. S. (2005). Teoriya i metodika pedagogicheskikh izmerenii: materialy publikatsii [Theory and methodology of pedagogical measurements: materials of publications]. Moscow: Center for testing and monitoring quality of education USTU-UPI.

2. Vyrodov, A. P., Kostarev, D. B., Kovaleva, S. V., \& Batrak, A. N. (2008). Primenenie metodov adaptivnoi gipermedia pri razrabotke avtomatizirovannykh obuchayushchikh sistem [Application of adaptive hypermedia methods in the development of automated training systems]. Visn. Mizhnar. slov'yan. un-tu. Ser. Tekhn. nauki (Jornal of International Slavic University. Ser.: Economic sciences), 11(1), 45-50

3. Galeev, I. Kh. (2004). Razvitie adaptivnykhtekhnologii obucheniya [Development of adaptive learning technologies]. Vestnik VGU (Proceedings of VSU), 4, 76-83.

4. Gaponova, V. M., \& Rabiichuk, L. S. (2002). Printsipi ta funktsii pedagogichnogo testovogo kontrolyu [Principles and functions of pedagogical test control]. In Collection of scientific works. Vol. 20, Part II (pp. 91-96). Khmel'nits'kii: Pub. National Academy of BSU.

5. Dobrovol's'kii, G. A., \& Savchenko, T. V. (2006). Algoritm stvorennya testovikh zavdan' [Algorithm for test tasks creating]. Zaporizhzhya: Zaporizhzhya National University.

6. Lukina, T. O. (2007). Tekhnologii diagnostiki ta otsinyuvannya navchal'nikh dosyagnen' [Technologies for diagnosis and evaluation of educational achievements]: educational materials. Kyiv: Ekspresob'yava.

7. Mintser, O. P. (2006). Avtomatizatsiya adaptivnikh protsesiv $\mathrm{v}$ sistemi distantsiinogo navchannya ta kontrolyu znan' [Automation of adaptive processes in the system of distance learning and knowledge control]. Elektronika i svyaz' (Electronics and communications), 3, 87-91.

8. Samylkina, N. N. (2007). Sovremennye sredstva otsenivaniya rezul'tatov obucheniya [Modern means of evaluating learning outcomes]. Moscow: BINOM, Laboratoriya znanii (Knowledge lab).

9. Titenko, S. V., \& Gagarin, O. O. (2008). Iierarkhichnomerezheva model' upravlinnya osvitnim kontentom sistemi bezperervnogo navchannya [An hierarchical network model for managing the educational content of the lifelong learning system]. In System analysis and information technology: materials of the 10th International Scientific and Technical Conference (Kiev, May 20-24, 2008). Kyiv: NTUU «KPI».

10.Topchiev, A. V., \& Chulyukov, V. A. (2010). Modeli adaptivnogo obucheniya $\mathrm{v}$ komp'yuternykh sistemakh [Models of adaptive learning in computer systems]. Sovremennye naukoemkie tekhnologii (Modern high technologies), 5, 62-68. 
11.Fedoruk, P. I. (2006). Ispol'zovanie adaptivnykh I intellektual'nykh tekhnologii $\mathrm{V}$ sistemakh distantsionnogo obucheniya [Using of adaptive and intelligent technologies in distance learning systems]. Upravlyayushchie sistemy I mashiny (Journal of control systems and machines), 5, 68-73.

12.Fedoruk, P. I. (2006). Adaptatsiya intelektual'nikh sistem distantsiinogo navchannya ta kontrolyu znan' do individual' nikh osoblivostei studentiv na osnovi analizu yakosti zasvoienikh znan' [Adaptation of intelligent systems of distance learning and control of knowledge to individual characteristics of students on the basis of analysis of the quality of acquired knowledge]. Shtuchnii intelekt (Artificial intelligence), 3, 480-486.

13.Fedoruk, P. I. (2006). Tekhnologiya predstavlennya modeli adaptivnoi sistemi distantsiinogo navchannya ta kontrolyu znan' [The technology of representing the model of the adaptive system of distance learning and knowledge control]. In Sistemi pidtrimki priinyattya rishen'. Teoriya i praktika (Decision support systems. Theory and practice): abstracts of the scientific-practical conference with international participation (pp. 186190). Kyiv: IMMS NASU.

14. Fedoruk, P. I. (2005). Tekhnologiya rozrobkinavchal'nogo modulya $\mathrm{v}$ adaptivnii sistemi distantsiinogo navchannya ta kontrolyu znan' [The technology of the bulkhead module in the adaptive system of distance learning and control]. Matematichni mashini i sistemi (Mathematical machines and systems), 3, 155-165.
15. Calvi, L., \& Cristea, A. (2002). Towards generic adaptive systems: analysis of a case study. In Proc. of the 2nd International Conf. on Adaptive Hypermedia and Adaptive Web-based Systems (Malaga, Spain, 2002) (pp. 79-89).

16. Dolog, P., \& Nejdl, W. (2003). Challenges and benefits of the semantic web for user modelling. In Proc. of AH2003 -Workshop on adaptive hypermedia and adaptive webbased systems. Twelfth International World Wide Web Conference, Budapest, Hungary, May 20, 2003. Ninth International Conference on User Modeling, Johnstown, Pennsylvania, USA, June 22, 2003. Fourteenth Conference on Hypertext and Hypermedia Nottingham, UK, August 26, 2003 (pp. 99-112).

17. One on one for everyone. The unique advantage of Knewton adaptive learning, (n. a.). Retrieved from Knewton website, https://www.knewton.com/approach/

18. Vasilakos, T., Devedzic, V., Kinshuk, K., \& Pedrycz, W.( 2004). Computational intelligence in web-based education: a tutorial. Journal of Interactive Learning Research (JILR), 15(4), 299-318.

19. Wu, H., De Bra, P. (2001). Sufficient conditions for wellbehaved adaptive hypermedia systems. In Proc. of the First Asia-Pac Conf. on Web Intelligence: Research and Development (Maebashi City, Japan, 2001) (pp. 148162). doi: 10.1007/3-540-45490-X_17. 